(C) 2018. This manuscript version is made available under the CC-BY-NC-ND 4.0 license http://creativecommons.org/licenses/by-nc-nd/4.0/

\title{
Biogas production from the liquid waste of distilled gin production: optimization of UASB reactor performance with increasing organic loading rate for co-digestion with swine wastewater.
}

Jesús A. Montes ${ }^{\mathrm{a}}$, Rubén Leivas ${ }^{\mathrm{b}}$, David Martinez-Prieto ${ }^{\mathrm{b}}$, Carlos Rico ${ }^{\mathrm{a}, *}$

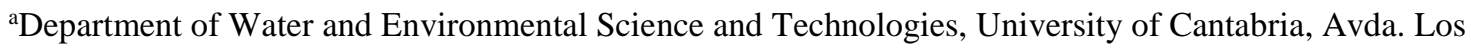
Castros, s/n, 39005, Santander, Spain

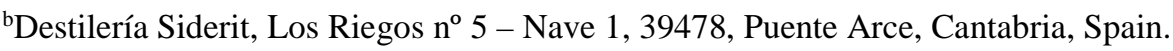

* Corresponding author. Tel.: +34 942201848; fax: +34 942201703.

E-mail address: ricoc@unican.es (Carlos Rico)

\section{Abstract}

This study is the first test that proves high rate anaerobic digestion as an efficient technological process for the treatment of gin spent wash. The gin spent wash was codigested in UASB reactors with swine wastewater, which provided nutrients and alkalinity. The process was optimized by increasing the proportion of gin spent wash in the feed, and thus the organic loading rate (OLR) up to reactor failure. Stable highefficiency operation was reached at an OLR as high as $28.5 \mathrm{~kg} \mathrm{COD} \mathrm{m}^{-3} \mathrm{~d}^{-1}$, yielding 8.4 $\mathrm{m}^{3} \mathrm{CH}_{4} \mathrm{~m}^{-3} \mathrm{~d}^{-1}$ and attaining a COD removal of $97.0 \%$. At an organic loading rate of $32.0 \mathrm{~kg} \mathrm{COD} \mathrm{m}^{-3} \mathrm{~d}^{-1}$, the process became unstable and the reactor underwent overacidification that drastically lowered the $\mathrm{pH}$ and suppressed methanogenesis. The failure of the reactor was caused by a combination of an organic overloading and alkalinity deficit that uncoupled acidogenesis and methanogenesis.

Keywords: Biochemical Methane Potential; COD/N ratio; Effluent recirculation; Granular sludge; Over-acidification; Volatile fatty acids. 


\section{Introduction}

The production of alcoholic beverages is one of the paramount industries around the world, both in terms of its economic value and as an engine for other sectors, in particular for agricultural production. The industry of production of alcoholic beverages is also a very important source of wastes worldwide. As regards spirits production, distillery spent wash (unwanted residual liquid waste) is considered the major liquid waste stream from the distilled beverage production due to its high Chemical Oxygen Demand (COD), high biodegradability and low pH (Acharya et al., 2008; Goodwin et al., 2001). The discharge of distillery wastewater into the environment before treatment is harmful and has high pollution potential including oxygen depletion in receiving water bodies, eutrophication, global warming and toxicity-related impacts (Mohana et al., 2009; Zang et al., 2015). On the other hand, distilleries are industries with an energy consumption that can be quite noticeable, mainly in the form of heat. Anaerobic digestion has been suggested as a feasible treatment process for distillery spent wash because its high organic pollution load can be converted into valuable methane gas (Barrena et al., 2018; Feng et al., 2017; Goodwin et al., 2001; Krishnamoorthy et al., 2017). The high temperature $\left(70-80^{\circ} \mathrm{C}\right)$ at which the spent wash is produced is another strong point to be considered because anaerobic digestion requires process temperatures between $35^{\circ} \mathrm{C}$ and $55^{\circ} \mathrm{C}$. Thus, anaerobic treatment could become a trend of great importance for the distillery industry in order to reduce the pollution potential of liquid wastes and, at the same time, complement the energy supply needed in the process by using the biogas produced. To deal with the high acidity and the high organic content of spent wash from other spirit beverages, treatment strategies have focused on dilution 
with water and external alkalinity supplementation (Goodwin and Stuart, 1994; López et al., 2018; Akunna and Clark, 2000).

Gin is a distilled spirit drink developed in northern Europe in the $17^{\text {th }}$ century. It is a colorless liquid containing at least $37.5 \%$ alcohol with a flavour principally derived from juniper berries. It has several types and formulations, London Dry Gin being the most popular. Distilled gin is traditionally made by distilling neutral alcohol in the presence of juniper berries and other botanical ingredients (Vichi et al., 2005). This production method is a traditional batch process that involves distillation in which the middle fraction of the distillate from the spirit still will become the final product. An undesirable waste product consisting of a mixture of spent botanics and liquid remains in the pot still. The liquid and the spent botanics can be easily separated and thus treated separately. The liquid part of this waste can be called gin spent wash (GSW).

To the best of our knowledge there are no previous studies dealing with the characteristics of the GSW, and in particular we are unaware of any focusing on biogas production and the main parameters affecting anaerobic digestion of this liquid waste. The distilled gin production process forecasts some features of the GSW in advance: low nutrient content because the only source of nutrients in the GSW proceeds from the botanics during distillation and absence of yeast cells as a consequence of using neutral alcohol as raw matter. On the other hand, similarly to other spirits' spent wash, the GSW should have high COD content and low pH.

The aim of this study was to evaluate the anaerobic treatment of GSW in UASB reactors. Because of the expected difficulties for the mono-digestion process, this first attempt has been performed in co-digestion mode with swine wastewater as co-substrate 
to provide nutrients and alkalinity to help in the anaerobic process without the addition of chemicals. Operation with the minimum content of swine wastewater in the influent and the highest stable organic loading rate was the final target of this study.

\section{Materials and methods}

\subsection{Substrates}

The GSW was collected between $24^{\text {th }}$ January and $25^{\text {th }}$ February 2018 from three different batches (GSW1, GSW2, GSW3) at Destilería Siderit, an emerging distillery located in Puente Arce (Cantabria, Spain). The swine wastewater (SWW) was obtained from a closed-cycle pig production farm and the total amount used in this experiment was provided on just one occasion, so that its composition did not change during the study. Both the GSW and the SWW were stored at $4^{\circ} \mathrm{C}$ in the laboratory until use. The characteristics of both substrates are given in Table 1.

Table 1. Characteristics of gin spent wash (GSW) and swine wastewater (SWW).

\begin{tabular}{ccc}
\hline Parameter & GSW & SWW \\
\hline TS (\%) & $10.4 \pm 1.0$ & $0.65 \pm 0.03$ \\
VS (\%) & $9.7 \pm 0.9$ & $0.26 \pm 0.02$ \\
COD $\left(\mathrm{g} \mathrm{L}^{-1}\right)$ & $168 \pm 22$ & $8.9 \pm 0.1$ \\
CODVFA $\left(\mathrm{g} \mathrm{L}^{-1}\right)$ & 0 & $5.9 \pm 0.1$ \\
pH & $4.2 \pm 0.2$ & $7.5 \pm 0.1$ \\
Alkalinity $\left(\mathrm{g} \mathrm{CaCO}_{3} \mathrm{~L}^{-1}\right)$ & --- & $10.0 \pm 0.1$ \\
$\mathrm{TN}\left(\mathrm{g} \mathrm{L}^{-1}\right)$ & $1.2 \pm 0.1$ & $2.0 \pm 0.1$ \\
$\mathrm{TAN}\left(\mathrm{mg} \mathrm{L}^{-1}\right)$ & $42 \pm 11$ & $1318 \pm 15$ \\
$\mathrm{TP}\left(\mathrm{mg} \mathrm{L}^{-1}\right)$ & $300 \pm 15$ & $640 \pm 6$ \\
BMP (L CH $\left.\mathrm{kg}^{-1} \mathrm{COD}\right)$ & $316 \pm 8$ & $202 \pm 5$ \\
\hline \multicolumn{2}{c}{ based on fresh matter. }
\end{tabular}




\subsection{UASB reactor}

Cylindrical lab-scale UASB reactors, made of plexiglass, with an operating volume of 1 L were used (1.3 L total volume). A stable reactor temperature was maintained at $36 \pm 1^{\circ} \mathrm{C}$ in the UASB reactor using a thermostat-controlled electric heating blanket. The biogas produced in the UASB reactor was collected daily in gas bags (Ritter GSB-P/22) and its volume was measured by connecting the gas bag to a liquid displacement system device. The UASB reactor was seeded with granular sludge from an industrial UASB reactor treating wastewaters from bioethanol production. Half of the reactor volume was filled with granules (12.9\% TS and 10.2\% VS).

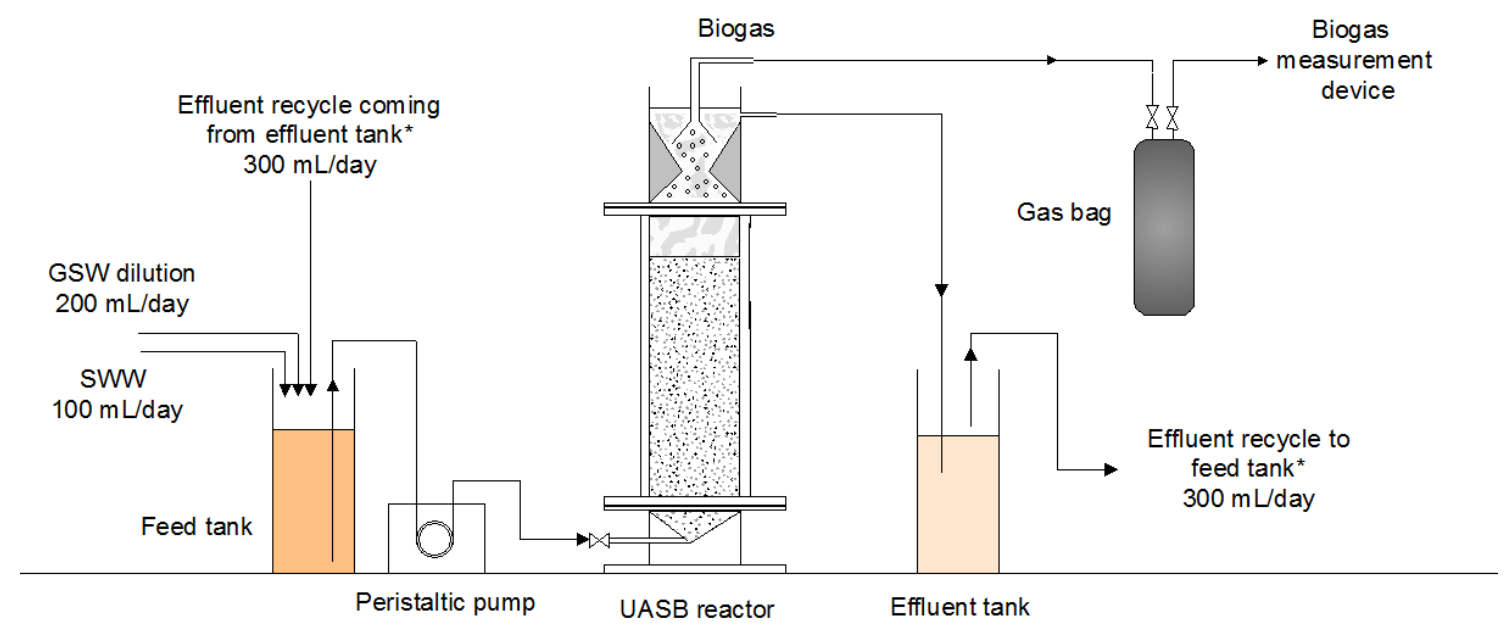

Figure 1. Experimental set-up scheme

\subsection{Mode of operation}

Fig. 1 shows the experimental set-up scheme of the process. The feed to the UASB reactor consisted of a mixture of the GSW diluted with dechlorinated tap water and the SWW. Every day, the feed tank was filled with $200 \mathrm{~mL}$ of the GSW dilution, $100 \mathrm{~mL}$ of SWW and $300 \mathrm{~mL}$ of effluent that were recycled from the effluent tank to dilute the 
influent and to provide extra alkalinity for the process. The process was optimized increasing the organic loading rate (OLR) by increasing the content of the GSW in the daily feed up to reactor failure, keeping the HRT as a constant at 3.3 days. With the first operating condition, a 10\% GSW dilution was used, being raised by $10 \%$ each time new conditions were assayed. These changes in the feed conditions (GSW content) were made after one week of operation at the current loading rate. The reactor was fed in semi-continuous mode in 15-minute cycles by means of a temporized peristaltic pump programmed to provide a daily flow of $600 \mathrm{~mL}$. Operating conditions are summarized in Table 2.

Table 2. Summary of operational conditions during UASB operation: Daily feed components and organic loading rates. $300 \mathrm{~mL}$ of effluent were mixed with the feed mixture in the influent tank.

\begin{tabular}{lcccccccc}
\hline Period & 1 & 2 & 3 & 4 & 5 & 6 & 7 & 8 \\
\hline Days & $1-7$ & $8-14$ & $15-20$ & $21-27$ & $28-34$ & $35-41$ & $42-50$ & $51-54$ \\
GSW (mL) & 20 & 40 & 60 & 80 & 100 & 120 & 140 & 160 \\
GSW sample & GSW1 & GSW1 & GSW1 & GSW1 & GSW2 & GSW3 & GSW3 & GSW3 \\
Water (mL) & 180 & 160 & 140 & 120 & 100 & 80 & 60 & 40 \\
SWW (mL) & 100 & 100 & 100 & 100 & 100 & 100 & 100 & 100 \\
$\begin{array}{l}\text { OLR (kg } \\
\text { COD } \mathbf{~ m}^{-3} \mathbf{d}^{-1} \text { ) }\end{array}$ & $3.9 \pm 0.0$ & $6.8 \pm 0.1$ & $9.6 \pm 0.1$ & $13.2 \pm 0.7$ & $18.0 \pm 1.2$ & $22.7 \pm 0.2$ & $28.5 \pm 0.4$ & $32.0 \pm 0.3$ \\
\hline
\end{tabular}

\subsection{Analytical techniques}

The volatile fatty acids (VFA) and the biogas composition were determined using a HP6890 gas chromatograph. The biogas and methane volumes are expressed at $0^{\circ} \mathrm{C}$ and standard pressure of $1 \mathrm{~atm}$ in dry conditions. Total Solids (TS), Volatile Solids (VS), 
Chemical Oxygen Demand (COD), Total Kjeldahl Nitrogen (TKN), Total Ammonia Nitrogen (TAN), Total Phosphorous (TP) and alkalinity were performed according to standard methods (APHA, 1998). The biochemical methane potential (BMP) tests were carried out following the methodology described in Valero et al. (2016).

\subsection{Data analysis}

Statistical significance was tested by ANOVA analysis, complemented with mean value comparison using Tukey’s HSD tests with a threshold P-value of 0.05 declared significant. Statistical significance was analyzed for data related to the relationship and ratios of OLR and both methane production and methane content in the biogas throughout the UASB experimentation.

\section{Results and discussion}

\subsection{Characteristics of the substrates}

The characteristics of the GSW and the SWW, depicted in Table 1, show very different properties. The GSW presents a very high organic content, with a mean COD of $168 \mathrm{~g}$ $\mathrm{L}^{-1}$ and a low $\mathrm{pH}$ of 4.2, which is both out of the optimal range (6.5-7.5), and too low for the anaerobic digestion process (Deublein and Steinhauser, 2011). In addition, the nutrient content of the GSW is quite tight for the anaerobic digestion process. The minimal nutrient requirements for the metabolism of the microorganisms is within a COD/N/P ratio of 800/5/1 (Deublein and Steinhauser, 2011). On the other hand, the COD of the SWW was only $8.9 \mathrm{~g} \mathrm{~L}^{-1}$, but its $\mathrm{pH}$ is in the optimal range for anaerobic digestion. Moreover, the SWW has a high alkalinity content to prevent $\mathrm{pH}$ drop and enough nutrient content to balance the global $\mathrm{C} / \mathrm{N} / \mathrm{P}$ ratio of the mixture for the codigestion process. The specific methane yield in terms of COD (SMY ${ }_{\mathrm{COD}}$ ) for GSW and 
SWW were 316 and $202 \mathrm{~L} \mathrm{CH}_{4} \mathrm{~kg}^{-1}$ COD respectively. The different COD contents of the three GSW samples (GSW1 150 g COD L $^{-1}$; GSW2 160 g COD L $^{-1}$; GSW3 $193 \mathrm{~g}$ $\mathrm{COD} \mathrm{L}^{-1}$ ) will have an effect on the volumetric methane production rate (VMPR) during UASB reactor operation. Summing up, the GSW has great potential for its conversion into energy in the form of biogas due to its high organic content. However, there are also process limitations due to lack of nutrients and acidity that would make its anaerobic mono-digestion very difficult or even unfeasible without a co-substrate, such as the SWW for example, or chemicals addition. In this regard, Ma et al. (2017) reported the synergistic effect for co-digestion of different feedstocks with animal manure.

\subsection{UASB reactor performance}

\subsubsection{Biogas and methane production}

The progression in the daily methane production can be observed in Fig. 2a. Each time feed conditions were modified, the daily methane yield increased due to the higher organic loading rate applied. The inertia of the process resulted in small increases in daily biogas and methane production on the second day of each condition as steady state conditions were reached. A bigger gap in daily methane production took place when the GSW source in the feed changed from GSW2 to GSW3 (day 32). As observed previously in the BMP determination of the GSW samples, the GSW3 presented a higher organic content that resulted in higher biogas and methane production values. The reactor was able to produce a maximum daily volume of $8.7 \mathrm{~L} \mathrm{CH}_{4}$ at day 50, when the system was fed with $140 \mathrm{~mL}$ per day of pure GSW3 (70\% dilution). When the last operation condition was set (80\% GSW in the dilution feed), the daily biogas and 
methane production started to drop, and fell to a minimal value $\left(0.4 \mathrm{~L} \mathrm{CH}_{4} \mathrm{~d}^{-1}\right)$ after four days, as result of which the reactor was stopped.
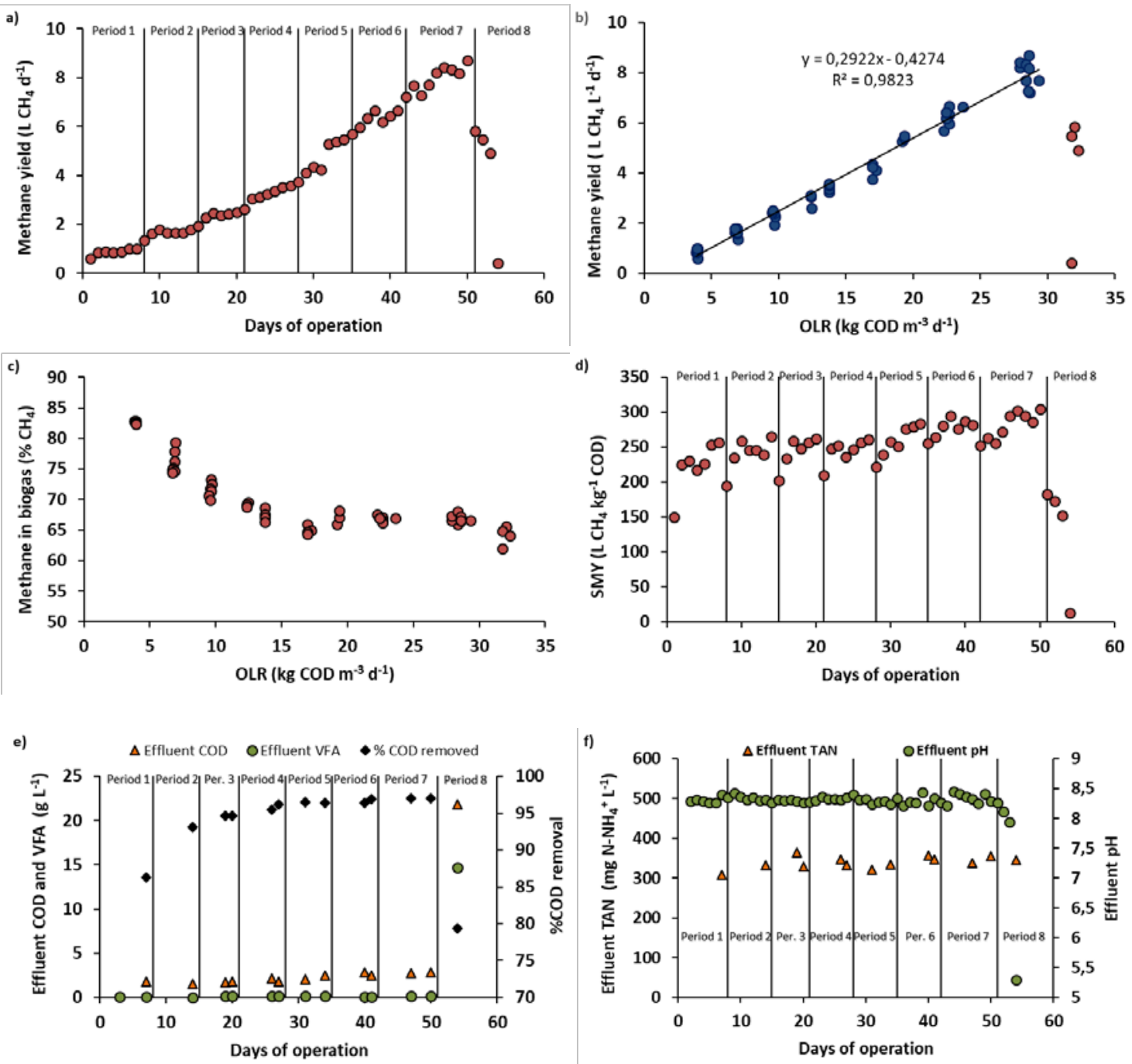

Figure 2. UASB reactor performance (a) Daily methane production along operation time (b) Volumetric methane production rate (VMPR) at different organic loading rates (blue circles represent operation for periods 1.7; red circles represent the period 8) (c) Methane content in biogas at different organic loading rates (d) Specific methane yield (SMY $\left.Y_{C O D}\right)$ along operation time (e) COD and COD $D_{V F A}$ in the effluent and removal percentage of COD ( $f$ ) Total Ammonia Nitrogen (TAN) and pH in the effluent with time. 
Fig. 2b represents the VMPR versus the OLR. Data represented in this figure show a very good relation between the OLR and the VMPR during operation periods 1-7 (blue circles in Fig. 2b). The OLR-VMPR ratio exhibited a strong correlation ( $\mathrm{p}<0.01)$. These data indicates that the efficiency of the process did not decrease with the augmentation of the OLR up to $28.5 \mathrm{~kg}$ COD m $\mathrm{m}^{-3} \mathrm{~d}^{-1}$. Red circles in Fig. 2b show the problems previously described at operation period 8 , when the OLR was set at $32.0 \mathrm{~kg}$ COD $\mathrm{m}^{-3} \mathrm{~d}^{-1}$ and the methane production dropped. Thus, a stable operation at a

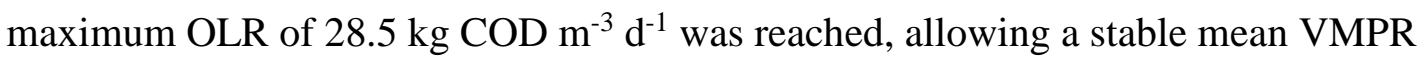
yield of $8.4 \mathrm{~m}^{3} \mathrm{CH}_{4} \mathrm{~m}^{-3} \mathrm{~d}^{-1}$.

The reactor produced a methane-rich biogas from the day one of operation, as Fig. 2c shows. As can be observed, at the lowest OLR applied, the quality of the biogas was very high $\left(82.9 \% \mathrm{CH}_{4}\right)$. The methane content in the biogas decreased in a linear way for the operation periods 1-4, just until GSW3 began to be used as feed. Methane content in the biogas dropped from $82.9 \%$ at an OLR of $3.9 \mathrm{~kg} \mathrm{COD} \mathrm{m}^{-3} \mathrm{~d}^{-1}$ to $65.0 \%$ at $17.1 \mathrm{~kg}$ COD m $\mathrm{m}^{-3} \mathrm{~d}^{-1}$. In this case, a negative correlation was observed between the methane content in the biogas and the OLR $(\mathrm{p}<0.05)$. The subsequent increase in biogas methane content (at a higher OLR) can be attributed to a different composition in the organic compounds coming from GSW3. A higher lipid content in GSW3 would explain the higher methane yield in terms of fresh matter in the BMP test (Alves et al. 2009) and the higher methane content at continuous UASB operation. In this regard, juniper berries and the rest of botanical materials contain terpenic compounds and essential oils (Vichi et al., 2008) that can lead to different composition of lipids in the GSW depending on distillation condition operations. 
Fig. 2d represents the methane yield per g of COD added (SMY). The different SMY ${ }_{\text {COD }}$ values of GSW and SWW obtained in the BMP test justify the intermediate value (about $0.25 \mathrm{~L} \mathrm{CH}_{4} \mathrm{~g}^{-1} \mathrm{COD}$ ) during the first half of the experimentation. In the second half of the experimentation, as GSW proportion in the feed increased, the value of $\mathrm{SMY}_{\mathrm{COD}}$ got closer to that of the GSW, reaching values around $0.3 \mathrm{~L} \mathrm{CH}_{4} \mathrm{~g}^{-1} \mathrm{COD}$ at experimental period 7. The higher contribution of GSW to the total COD of the feed mixture is the reason for this effect. The high SMY ${ }_{C O D}$ value is evidence of the high reactor performance until the last operation condition was set, since the maximum $\mathrm{SMY}_{\mathrm{COD}}$ that an anaerobic system process can yield is $0.35 \mathrm{~L} \mathrm{CH}_{4} \mathrm{~g}^{-1} \mathrm{COD}$. Analogously to the daily biogas and methane production and the VMPR, the SMY ${ }_{C O D}$ also dropped at the last experimental condition.

\subsubsection{COD removal efficiency and VFA in the effluent}

Both the COD and the VFA of the effluent were analyzed at the end of each experimental condition. The values of VFA, COD in the effluent and the COD removal efficiency are shown in Fig. 2e. The presence of VFA in the effluent was negligible during experimental periods 1-7. The presence of acetic and propionic acids was minimal with concentrations lower than $200 \mathrm{mg} \mathrm{COD}_{\mathrm{VFA}} \mathrm{L}^{-1}$. With regard to effluent COD and COD removal percentage, the effluent COD ranged between 1.5 and $2.8 \mathrm{~g}$ COD L ${ }^{-1}$ during experimental periods 1-7. The values of the effluent COD showed an increment trend throughout the operation days that was motivated by the increases in the OLR applied to the reactor. The COD removal efficiency increased with the OLR because of the higher biodegradability of the GSW compared to that of the SWW. Consequently, COD removal percentages higher than 95\% were achieved from the third experimental condition. This parameter reached a maximum value of $97.0 \%$ at the last 
stable operation condition (OLR $28.5 \mathrm{~kg} \mathrm{COD} \mathrm{m}^{-3} \mathrm{~d}^{-1}$ ). These results are in accordance with the methane yielded by the reactor, showing high efficiency reactor process performance. The day the reactor was stopped, the VFA concentration in the effluent had risen to $14.7 \mathrm{~g} \mathrm{COD}_{\mathrm{VFA}} \mathrm{L}^{-1}$, with acetic acid (8.6 $\mathrm{g} \mathrm{CODVA}_{\mathrm{VFA}}^{-1}$ ) being the major VFA, followed by butyric (3.2 g COD VFA $\left.\mathrm{L}^{-1}\right)$ and propionic $\left(1.0 \mathrm{~g}_{\mathrm{COD}} \mathrm{VFA}^{-1}\right)$. In this specific context, the presence of these compounds is clear evidence of reactor failure by over-acidification.

\subsubsection{COD/N ratio, $\mathrm{pH}$ and alkalinity}

The COD/N ratio in the feed for the first experimental period was $17.6 / 1$. This ratio increased with the OLR due to the increasing proportion of GSW in the feed, passing to a value of $76.4 / 1$ at experimental period 7 and to 81.6/1 at the last experimental period, when over-acidification occurred. According to Deublein and Steinhauser (2011), the optimal COD/N ratio for the methanization stage is within the range 60-90/1. However, an organic matter ratio of COD/N as high as 160/1 can be sufficient for the sustainability of the process. The results of this work show that process performance was not hindered by COD/N ratios below the optimal range because the efficiency of the process was similar within the aforementioned experimental ranges. In this regard, Guarino et al. (2016) also observed that the $\mathrm{C} / \mathrm{N}$ ratio did not affect the methane yield during anaerobic digestion of buffalo manure. The higher VMPR and SMY ${ }_{\text {COD }}$ values can be attributed to the higher contribution of GSW in the feed mixture rather than the better $\mathrm{COD} / \mathrm{N}$ ratio. A low $\mathrm{COD} / \mathrm{N}$ ratio can lead to increased ammonia production and inhibition of methane production. However, this is not the case as TAN levels in the effluent were always in the range 300-400 mg TAN L $^{-1}$ (Fig 2f), which are below typical ammonia inhibition levels of $1.7 \mathrm{~g} \mathrm{TAN} \mathrm{L}^{-1}$ (Chen et al., 2008). This data also 
reveals that the increasing amounts of GSW in the feed did not have an influence in the effluent TAN concentration, so that the TAN concentration in the media proceeded mainly from the SWW. The pH of the effluent fluctuated between 8.2 and 8.4 along experimental periods 1-7. When the last operational condition started, the $\mathrm{pH}$ dropped to 8.1 and 7.9 on the following days and finally fell down to 5.3 the day the reactor was stopped, which confirms reactor failure owing to over-acidification. The effluent alkalinity fluctuated between $2500 \mathrm{mg} \mathrm{CaCO}_{3} \mathrm{~L}^{-1}$ at the first operation condition and $3600 \mathrm{mg} \mathrm{CaCO} 3 \mathrm{~L}^{-1}$ at experimental condition 7. Although degradation of organic matter produces acids that destroy alkalinity, the alkalinity is later returned when methane fermentation occurs. Thus, when the process performs at high efficiency, as in this case, the higher organic loading rate brought about higher alkalinity in the effluent.

Despite the fact that the VFA/alkalinity ratio allows the detection of changes in the stability of an anaerobic digestion process (Rozzi et al., 1994), the negligible concentration of VFA in the effluent during operational periods 1-7 did not warn about the ulterior over-acidification in the period 8. In this sense, an analysis of VFA during the first days of operation of period 8 would have served as an indicator of process instability. However, the drop in the $\mathrm{pH}$ below 8 the day before process failure can also be interpreted as a signal of instability. Thus, the $\mathrm{pH}$ together with the volumetric methane production rate can be used to control and monitor the process. In this case, the last increment in the OLR caused an imbalance between acidogenic and methanogenic stages by organic overloading that could not be compensated with the alkalinity in the medium, causing VFA accumulation, along with a big drop in the $\mathrm{pH}$ and inhibition of methanogenesis, with the consequence of an irreversible reactor failure by overacidification. To cope with this problem, additional alkalinity should be provided by 
increasing the proportion of SWW in the feed or by increasing the effluent recirculation to influent ratio.

\section{Conclusions}

Gin spent wash can be efficiently treated in UASB reactors by co-digestion with wastewaters that provide alkalinity and nutrients. Process performance at organic loading rates as high as $28.5 \mathrm{~kg} \mathrm{COD} \mathrm{m}^{-3} \mathrm{~d}^{-1}$ suggests technical feasibility for future industrial applications. The results have also shown that methane production rates and effluent $\mathrm{pH}$ can be used to monitor the process to prevent against over-acidification. Overall, this process can contribute to the generation of energy in the distilled gin industry, turning a pollution problem into energy to complement the energy supply needed in the distillery by using the biogas produced.

\section{Acknowledgements}

This research was supported by Destilería Siderit in the framework of the Innova Program in the Autonomous Community of Cantabria. 


\section{References}

Acharya, N.K., Mohana, S., Madamwar, D., 2008. Anaerobic treatment of distillery spent wash - A study on upflow anaerobic fixed film bioreactor. Bioresour. Technol. 99, 4621-4626.

Akunna, J.C., Clark, M., 2000. Performance of a granular-bed anaerobic baffled reactor (GRABBR) treating whisky distillery wastewater. Bioresour. Technol. 74, 257-261.

Alves, M., Alcina Pereira, M., Sousa, D.Z., Cavaleiro, A.J., Picavet, M., Smidt, H., Stams, A., 2009. Waste lipids to energy: how to optimize methane production from long-chain fatty acids (LCFA). Microbial Biotechnol. 2, 538-550.

APHA, 1998. Standard Methods for the Examination of Water and Wastewater, $20^{\text {th }}$ ed. American Public Health Association, Washington, USA.

Barrena, R., Traub, J.E., Rodriguez Gil, C., Goodwin, J.A.S., Harper, A.J., Willoughby, N.A., Sánchez, A., Aspray, T.J., 2018. Batch anaerobic digestion of deproteinated malt whisky pot ale using different source inocula. Waste Manage. 71, 675-682.

Chen, Y., Cheng, J.J., Creamer, K.S., 2008. Inhibition of anaerobic digestion process: a review. Bioresour. Technol. 99, 4044-4064.

Deublein, D., Steinhauser, A., 2011. Biogas from Waste and Renewable Resources: an Introduction. John Wiley \& Sons.

Feng, Q., Song, Y.C., Yoo, K., Kuppanan, N., Subudhi, S., Lal, B., 2017.

Bioelectrochemical enhancement of direct interspecies electron transfer in upflow 
anaerobic reactor with effluent recirculation for acidic distillery wastewater. Bioresour. Technol. 241, 171-180.

Goodwin, J.A.S., Finlayson, J.M., Low, E.W., 2001. A further study of the anaerobic biotreatment of malt whisky distillery pot ale using an UASB system. Bioresour. Technol. 78, 155-160.

Goodwin, J.A.S., Stuart, J.B., 1994. Anaerobic digestion of malt whisky distillery pot ale using upflow anaerobic sludge blanket reactors. Wat. Sci. Technol. 49, 75-81.

Guarino, G., Carotenuto, C., di Cristofaro, F., Papa, S., Morrone, B., Minale, M., 2016. Does the $\mathrm{C} / \mathrm{N}$ ratio really affect the Bio-methane Yield? A three years investigation of Buffalo Manure Digestion. Chem. Eng. Trans. 49, 463-468.

Krishnamoorthy, S., Premalatha, M., Vijayasekaran, M., 2017. Characterization of distillery wastewater - An approach to retrofit existing effluent treatment plant operation with phycoremediation. J. Clean. Prod. 148, 735-750.

López, I., Borzacconi, L., Passeggi, M., 2018. Anaerobic treatment of sugar cane vinasse: treatability and real-scale operation. J. Chem. Technol. Biotechnol. 93, $1320-1327$.

Ma, G., Neibergs, J.S., Harrison, J.H., Whitefield, E.M., 2017. Nutrient contributions and biogas potential of co-digestion of feedstocks and dairy manure. Waste Manage. 64, 88-95.

Mohana, S., Acharya, B.K., Madamwar, D., 2009. Distillery spent wash: Treatment technologies and potential applications. J. Hazard. Mater. 163, 12-25. 
Rozzi, A., Di Pinto, A.C., Limoni, N., Tomei, M.C., 1994. Start-up and operation of anaerobic digesters with automatic bicarbonate control. Bioresour. Technol. 48, 215219.

Valero, D., Montes, J.A., Rico, J.L., Rico, C., 2016. Influence of headspace pressure on methane production in Biochemical Methane Potential (BMP) tests. Waste Manage. 48, 193-198.

Vichi, S., Riu-Aumatell, M., Mora-Pons, M., Buxaderas, S., López-Tamames, E., 2005. Characterization of Volatiles in Different Dry Gins. J. Agric. Food Chem. 53, $10154-10160$.

Vichi, S., Riu-Aumatell, M., Mora-Pons, M., Buxaderas, S., López-Tamames, E., 2008. Assessment of some diterpenoids in commercial distilled gin. Anal. Chim. Acta 628, $222-229$.

Zang, Y., Li, Y., Wang, C., Zhang, W., Xiong, W., 2015. Towards more accurate life cycle assessment of biological wastewater treatment plants: a review. J. Clean. Prod. 107, 676-692. 